\title{
Editorial
}

\section{Toward a Green, Closed-Loop, Circular Bioeconomy: Boosting the Performance Efficiency of Circular Business Models}

\author{
Charisios Achillas ${ }^{1, *}$ and Dionysis Bochtis ${ }^{2}$ (I) \\ 1 Department of Supply Chain Management, School of Economics and Business Administration, \\ International Hellenic University, GR 60100 Katerini, Greece \\ 2 Institute for Bio-Economy and Agri-Technology (iBO), Center for Research and Technology-Hellas (CERTH), \\ 6th km Charilaou-Thermi Rd, GR 57001 Thermi, Greece; d.bochtis@certh.gr \\ * Correspondence: c.achillas@ihu.edu.gr; Tel.: +30-23510-47860
}

Received: 2 December 2020; Accepted: 3 December 2020; Published: 4 December 2020

In recent years, bioeconomy strategies have been successfully implemented and widely adopted internationally. Such strategies have been promoted, mostly in an effort to combat and confront climate change, which is considered not only an ecological question, but "the most systemic threat to humankind", as characterized by the UN Secretary-General in 2018, and also a critical point towards global security and freedom [1,2]. Moreover, resource scarcity is also considered an additional critical issue at present. The pressures imposed by economic development and the expansion of the global population places the problem of the intensification of raw material use and resource scarcity at the epicenter of the discussion on global sustainability for generations to come [3].

Within the bioeconomy, materials are, to a certain extent, circular by nature. However, biomaterials may be also used in a rather linear way. Lately, a transition towards a circular economy has been promoted worldwide. In brief, circular business models are targeting the establishment of a more restorative and-at the same time-regenerative system, where material inputs, energy use, waste production, and emissions to the natural environment are minimized, if not eradicated, by narrowing and closing material and energy loops. The aim is to efficiently utilize materials by extracting the maximum value from them whilst in use, providing yield for as long as possible, and recovering their residual values at the end of their useful lifetimes [4,5]. In this context, a circular economy offers an alternative model aimed at "doing more and better with less" on a life cycle basis (life cycle thinking), in contrast to the traditional linear model that is based on the "take-make-dispose" production and consumption strategies.

More specifically, circularity is based on the idea of redistributing matter and energy in an effort to diminish the need for new inputs in supply chains. The concept lies in maintaining the value of products, materials, and resources for as long as possible and, at the same time, minimizing, or even eliminating, the amount of waste produced. This can be achieved only through the application of modifications to the design of products or services, so as to increase their useful lifetimes, upgrade their maintainability (e.g., through the adoption of the Design for Disassembly approach), support their reuse potential, either as a full product or partially, with the refurbishment and reuse of their components, while also improve recyclability and upcycling.

Focused on the "closing the loop" philosophy, the circular economy is a practical solution for promoting entrepreneurial sustainability, economic growth, environmental resilience, and a better quality of life for all. The most efficient way to close resource loops is to find value in the waste [6]. In this light, nothing is regarded as waste; on the contrary, everything is viewed as a resource with a residual value that can be reintroduced and exploited within the same or a different supply chain. 
In practice, a number of different modes of resource circulation may be applied. Closing the loop can be applied to raw materials, by-products, human resources, logistics, services, waste, energy, and water.

The benefits that derive from the adoption of circular economy models are critical towards economic development and public prosperity. In particular, the application of circular economic models reduces the requirements for raw materials, water use, and energy dependency, creating significant savings by better controlling and reducing operational costs, thus improving business competitiveness. Moreover, such models typically result in the upgrade of supply chain security since organizations are far less dependent on external inputs. Apart from the economic benefits, the adoption of circular economy models also results in significant environmental and social benefits, enhancing sustainability. The extraction of raw materials, waste quantities, and emissions are minimized, decreasing the pressure imposed on the natural environment; greenhouse gas emissions are abated, contributing to internationally agreed-upon policies against climate change and global warming; employment opportunities arise in newly established sectors, while new business opportunities are formed through the development of novel products and services that link the output and waste of one entity to the required input for another [7-11].

At an international level, circularity has been expanded relatively recently. Although initially coined as a term in the 1970s, the circular economy attracted the intensified interest of major, multinational producers and policymakers only during recent years. Across the world, key stakeholders are eager to shift from linearity to circularity, primarily in order to enhance the competitiveness of the business environment under strict restrictive environmental conditions and a fast technological transformation $[12,13]$. The introduction of circular economy models lies mostly on four key action areas, namely primary and industrial production, consumption of goods, management of waste, and exploitation of secondary raw materials. Currently, circularity is widely applied primarily to business sectors, such as the plastics industry, the raw materials sector, the construction (and demolition) industry, as well as to the food industry, and fields related to the bioeconomy, such as the production of biomass and bio-based products [14]. The increasingly stricter environmental legislation and policies at an international level, together with prevailing "green" initiatives worldwide, have triggered the necessity for the development of a circular ecosystem on a global scale. To that end, policy and legal frameworks have been established in more and more countries in the developed and the developing world, in the effort to support the exploitation of waste, its reuse, refurbishment, or recycling and reintroduction to similar or other supply chains and production processes.

Of course, the adoption of circular economy models requires collective effort and teamwork. No single organization or enterprise can efficiently apply circular economy practices on their own. The circular economy is highly dependant on the exchange of knowledge and experiences between stakeholders, while thriving on business networks and the application of industrial symbiotic practices. In this context, the only path for each entity to succeed in minimizing waste and exploiting secondary resources includes cooperation with other players who have a similar mentality and seek work in the same direction, or better yet, are already a few steps ahead.

Undoubtedly, the predominance of the circular economy in the field of bioeconomy requires the active involvement of all types of stakeholders within the quadruple helix, namely government, industry, academia, and civil society [15-17]. Moreover, the prevalence of circular business models over linear ones necessitates the adoption of multidisciplinary scientific and technical approaches [18]. This Special Issue aims to bring to light novel production systems, innovative design processes, and pioneering engineering advancements. The thirteen (13) articles that are published in the Special Issue efficiently contribute to the circular bioeconomy agenda through enhanced scientific and multidisciplinary knowledge. It is evident that contributions related to innovative technical developments, reviews, and case studies effectively boost the performance efficiency of circular business models, and support decision-making within the field of green, closed-loop, circular bio-economies. In brief, the contributions span around topics related to sustainability, agri-business, life cycle thinking, green production, reverse logistics, waste management, bioresources, bioenergy, and a bioeconomy. 
The thematic areas that are discussed within the Special Issue cover views and attitudes on a bioeconomy, policymaking and decision-making in the circular economy, social issues related to the topic, and also reviews and secondary sources that synthesize and analyze research already conducted in the field.

More specifically, three (3) articles included in the Special Issue deal with "views and attitudes on the bioeconomy". In particular, Purwestri et al. conducted a preliminary assessment of a survey utilized in the Czech Republic on the bioeconomy, as part of a nationwide relevant survey [19]. The article focuses on wood and non-wood forest products. The work aims to provide an initial evaluation regarding the use of forest products and related factors, and to make recommendations on developing wood consumption and promoting other forest ecosystem services for the adoption of a forest bioeconomy strategy in the Czech Republic. The survey revealed the challenge to switch the practice from using fossil-based heating to a wood boiler energy source. Moreover, turning wood into products with a high added-value is highly recommended. The promotion of wood and non-wood forest products is encouraged, starting with increasing awareness and knowledge of the strength of the forest-based sector as a renewable energy resource and the importance of forest ecosystem services, using different channels as sources of information. On a similar topic, Priefer and Meyer examine the way that scientists think about the concept of a bioeconomy in Germany [20]. In this work, an online survey was carried out among scientists involved in a regional bioeconomy research program in southern Germany in order to gain insight into their understanding of a bioeconomy. Moreover, the survey provided information about cooperation and major challenges in the future development of three biomass utilization pathways: biogas, lignocellulose, and microalgae. The analysis showed that a resource-oriented understanding of a bioeconomy is favored. The political objectives for a European bioeconomy are widely accepted, and it is expected that ongoing research can significantly contribute to achieving these goals. The two different pathways for shaping the bioeconomy that are discussed in the debate-the technology-based approach and the socio-ecological approach-are considered compatible rather than contrary. Within the same topic, Fiore et al. present the key findings of the InnovaEcoFood project, which focuses on the use of by-products of the Piedmontese rice and wine production chains to valorize their untapped potential in the food sector by identifying how value could be created from the waste [21].

An additional six (6) contributions are related to the thematic area of "policymaking and decision-making" in the field of the circular economy. In particular, Singh et al. evaluate the effectiveness of climate change adaptations in the Sundarbans, the world's largest coastal river delta and the largest uninterrupted mangrove ecosystem [22]. With the use of a fuzzy cognitive maps-based approach, the authors aim to elicit and integrate stakeholders' perceptions regarding current climate forcing, consequent impacts, and efficacy of the existing adaptation measures. The simulations revealed that while existing adaptation practices provide resilience to an extent, they are grossly inadequate in the context of providing future resilience, and adaptations may not be entirely transformative in such a fragile ecosystem. According to the authors, measures that are likely to enhance adaptive capabilities of the local communities include those involving gender-responsive and adaptive governance, human resource capacity building, commitments of global communities for adaptation financing, education and awareness programs, and embedding indigenous and local knowledge into decision making.

Ovezikoglou et al. focus on the funding mechanisms of circular interventions and specifically on the development of a novel methodological scheme for the sustainability assessment of alternative investments with the use of indicators, based on a Multiple Criteria Methodological Framework [23]. A number of alternative indicators are proposed, assessed over four criteria (environment, society, economy, and technology), and hierarchized in order to select the optimal bundle to be used for the assessment of future industrial investments. The analysis results in the fact that "Resource Savings" is the criterion that optimally characterizes the sustainability of an investment in a bioeconomy, coupled with "Recycling" and "Research, Innovation, Development" indicators. 
Anagnostis et al. turned their attention to the application of artificial neural networks for natural gas consumption forecasting [24]. The study explores different types of neural network approaches for forecasting natural gas consumption in cities across Greece. A comparative analysis is conducted between the selected networks, in an effort to better understand individual locations' characteristics and public habitual patterns.

Kyriakarakos et al. propose a paradigm shift in rural electrification investments in Sub-Saharan Africa through agriculture [25] Since a large number of people around the world still do not have access to electricity, private sector investments and new innovative business models are required. In this direction, microgrid electrification in rural areas with the active involvement of agriculture-related businesses is proposed by the authors, and financing of such activities is investigated in the specific work. The analysis results in the fact that the high costs of rural electrification can be met through the increased value of locally produced products. At the same time, cross-subsidization can take place to decrease the cost of household electrification.

The work of Katchova and Sant'Anna puts emphasis on the location of ethanol plants and the impact of that decision on corn revenues for U.S. farmers [26]. Specifically, the opening of an ethanol plant may increase local demand for corn, pressuring increases in the local corn basis. The question that is answered in this manuscript is what the effect of location on corn contract prices and revenues is. The authors conclude that policymakers should focus their resources on promoting greater efficiency in corn production to boost farmers' revenues.

Chastain concentrates on ammonia volatilization losses during the irrigation of liquid animal manure [27]. Ammonia loss resulting from land application of liquid animal manure varies depending on the composition of the manure and the method used to apply manure to cropland. High levels of ammonia volatilization result in an economic loss to the farmer, based on the value of the nitrogen, and have also been shown to be a source of air pollution. Using irrigation as a method of applying liquid manure to cropland has generally been accepted as a method that increases the volatilization of ammonia. Through measurements, and in line with previous studies on irrigation performance, Chastain concludes with the fact that volatilization losses during irrigation were not found to be statistically significant, and evaporation losses were small.

Within the topic of "social issues" related to bioeconomy, two (2) articles have been published. Papageorgiou et al. propose a fuzzy cognitive map-based sustainable socio-economic development plan for rural communities [28]. Specifically, fuzzy cognitive maps are recommended to be employed by policymakers-as a powerful and easy-to-use tool for representing complex systems-in order to keep human activities within a safe limit of the planetary boundaries. The work studies a complex phenomenon of poverty eradication and socio-economic development strategies in rural areas in India, and various scenarios examining the economic sustainability and livelihood diversification of poor women in rural areas were performed. With a similar concept, Bochtis et al. extensively discuss the agricultural workforce crisis in light of the recent COVID-19 pandemic, which seriously affected the agricultural workforce and jeopardized food security [29]. The work aims at assessing the COVID-19 pandemic impacts on agricultural labor and suggests strategies to mitigate them. Following an analytic research methodology related to the benchmarking of risks to agricultural workers by individual tasks within agricultural production, depending on a number of key criteria, the authors conclude that a series of control measures need to be adopted so as to enhance the resilience and sustainability of the sector, as well as to protect farmers with physical distancing, hygiene practices, and personal protection equipment.

There are also two (2) review articles that contribute to the topic. Lampridi et al. propose a methodological framework for the systematic literature review of agricultural sustainability studies [30]. The framework synthesizes all the available literature review criteria and introduces a two-level analysis facilitating systematization, data mining, and methodology analysis. The proposed framework is validated for the systematic review of 38 crop agricultural sustainability assessment studies at the farm level within the last decade. Moreover, Angelopoulou et al. review the progress made in the last 
decade in respect to laboratory and proximal sensing spectroscopy in the visible and near infrared and shortwave infrared (VNIR-SWIR) wavelength region for soil organic carbon and soil organic matter estimation as an alternative to analytical chemistry measurements [31]. The results of over fifty selective studies are critically discussed and the factors that affect the accuracy of spectroscopic measurements for both laboratory and in situ applications are analyzed.

It is the editors' strong belief that the material included in the present Special Issue bridges part of the gap between the bioeconomy on one hand and green supply chains, closed-loop systems, and the circular economy on the other. As thoroughly discussed in this editorial, as well as in the contributing manuscripts that are included in the Special Issue, the only efficient way to close resource loops is to find value in the waste. It is evident that shifting from conventional, linear business modules to circular ones is a prerequisite for sustainable development and the achievement of the internationally acknowledged Sustainable Development Goals.

Author Contributions: Conceptualization: C.A. and D.B.; Writing-original draft preparation C.A. and D.B.; Writing-review and editing: C.A. and D.B. All authors have read and agreed to the published version of the manuscript.

Funding: This research received no external funding.

Conflicts of Interest: The authors declare no conflict of interest.

\section{References}

1. Aguiar, A.P.D.; Collste, D.; Harmáčková, Z.V.; Pereira, L.; Selomane, O.; Galafassi, D.; Van Vuuren, D.; Van Der Leeuw, S. Co-designing global target-seeking scenarios: A cross-scale participatory process for capturing multiple perspectives on pathways to sustainability. Glob. Environ. Chang. 2020, 65, 102198. [CrossRef]

2. Shrivastava, P.; Stafford Smith, M.; O’Brien, K.; Zsolnai, L. Transforming Sustainability Science to Generate Positive Social and Environmental Change Globally. One Earth 2020, 2, 329-340. [CrossRef]

3. Nyam, Y.S.; Kotir, J.H.; Jordaan, A.J.; Ogundeji, A.A.; Adetoro, A.A.; Orimoloye, I.R. Towards Understanding and Sustaining Natural Resource Systems through the Systems Perspective: A Systematic Evaluation. Sustainability 2020, 12, 9871. [CrossRef]

4. Banias, G.; Achillas, C.; Vlachokostas, C.; Moussiopoulos, N.; Stefanou, M. Environmental impacts in the life cycle of olive oil: A literature review. J. Sci. Food Agric. 2017, 97, 1686-1697. [CrossRef] [PubMed]

5. Tsarouhas, P.; Achillas, C.; Aidonis, D.; Folinas, D.; Maslis, V. Life Cycle Assessment of olive oil production in Greece. J. Clean. Prod. 2015, 93, 75-83. [CrossRef]

6. Achillas, C.; Moussiopoulos, N.; Karagiannidis, A.; Banias, G.; Perkoulidis, G. The use of multi-criteria decision analysis to tackle waste management problems: A literature review. Waste Manag. Res. 2013, 31, 115-129. [CrossRef]

7. Jarosch, L.; Zeug, W.; Bezama, A.; Finkbeiner, M.; Thrän, D. A Regional Socio-Economic Life Cycle Assessment of a Bioeconomy Value Chain. Sustainability 2020, 12, 1259. [CrossRef]

8. Bochtis, D.D.; Sørensen, C.G.; Busato, P.; Berruto, R. Benefits from optimal route planning based on B-patterns. Biosyst. Eng. 2013, 115, 389-395. [CrossRef]

9. Rodias, E.; Berruto, R.; Busato, P.; Bochtis, D.; Sørensen, C.G.; Zhou, K. Energy savings from optimised in-field route planning for agricultural machinery. Sustainability 2017, 9, 1956. [CrossRef]

10. de Schutter, L.; Giljum, S.; Häyhä, T.; Bruckner, M.; Naqvi, A.; Omann, I.; Stagl, S. Bioeconomy Transitions through the Lens of Coupled Social-Ecological Systems: A Framework for Place-Based Responsibility in the Global Resource System. Sustainability 2019, 11, 5705. [CrossRef]

11. Rodias, E.C.; Lampridi, M.; Sopegno, A.; Berruto, R.; Banias, G.; Bochtis, D.D.; Busato, P. Optimal energy performance on allocating energy crops. Biosyst. Eng. 2019, 181, 11-27. [CrossRef]

12. Duquet, B.; Brunelle, C. Subcentres as Destinations: Job Decentralization, Polycentricity, and the Sustainability of Commuting Patterns in Canadian Metropolitan Areas, 1996. Sustainability 2020, 12, 9966. [CrossRef]

13. Marinoudi, V.; Sørensen, C.G.; Pearson, S.; Bochtis, D. Robotics and labour in agriculture. A context consideration. Biosyst. Eng. 2019, 184, 111-121. [CrossRef] 
14. Tomaszewska, J. Polish Transition towards Circular Economy: Materials Management and Implications for the Construction Sector. Materials (Basel) 2020, 13, 5228. [CrossRef]

15. Feleki, E.; Vlachokostas, C.; Achillas, C.; Moussiopoulos, N.; Michailidou, A.V. Involving decision-makers in the transformation of results into urban sustainability policies. Eur. J. Environ. Sci. 2016, 6, 7-10. [CrossRef]

16. Marting Vidaurre, N.A.; Vargas-Carpintero, R.; Wagner, M.; Lask, J.; Lewandowski, I. Social Aspects in the Assessment of Biobased Value Chains. Sustainability 2020, 12, 9843. [CrossRef]

17. Dieken, S.; Venghaus, S. Potential Pathways to the German Bioeconomy: A Media Discourse Analysis of Public Perceptions. Sustainability 2020, 12, 7987. [CrossRef]

18. Barragán-Ocaña, A.; Silva-Borjas, P.; Olmos-Peña, S.; Polanco-Olguín, M. Biotechnology and Bioprocesses: Their Contribution to Sustainability. Processes 2020, 8, 436. [CrossRef]

19. Purwestri, R.C.; Hájek, M.; Šodková, M.; Jarskỳ, V. How arewood and non-wood forest products utilized in the Czech Republic? A preliminary assessment of a nationwide survey on the bioeconomy. Sustainability 2020, 12, 566. [CrossRef]

20. Priefer, C.; Meyer, R. One concept, many opinions: How scientists in Germany think about the concept of bioeconomy. Sustainability 2019, 11, 4253. [CrossRef]

21. Fiore, E.; Stabellini, B.; Tamborrini, P. A systemic design approach applied to rice and wine value chains. The case of the innovaecofood project in piedmont (italy). Sustainability 2020, 12, 9272. [CrossRef]

22. Singh, P.K.; Papageorgiou, K.; Chudasama, H.; Papageorgiou, E.I. Evaluating the effectiveness of climate change adaptations in the world's largest Mangrove Ecosystem. Sustainability 2019, 11, 6655. [CrossRef]

23. Ovezikoglou, P.; Aidonis, D.; Achillas, C.; Vlachokostas, C.; Bochtis, D. Sustainability assessment of investments based on a multiple criteria methodological framework. Sustainability 2020, 12, 6805. [CrossRef]

24. Anagnostis, A.; Papageorgiou, E.; Bochtis, D. Application of artificial neural networks for natural gas consumption forecasting. Sustainability 2020, 12, 6409. [CrossRef]

25. Kyriakarakos, G.; Balafoutis, A.T.; Bochtis, D. Proposing a paradigm shift in rural electrification investments in Sub-Saharan Africa through Agriculture. Sustainability 2020, 12, 3096. [CrossRef]

26. Katchova, A.L.; Sant'Anna, A.C. Impact of Ethanol plant location on corn revenues for U.S. Farmers. Sustainability 2019, 11, 6512. [CrossRef]

27. Chastain, J.P. Ammonia volatilization losses during irrigation of liquid animal manure. Sustainability 2019, 11, 6168. [CrossRef]

28. Papageorgiou, K.; Singh, P.K.; Papageorgiou, E.; Chudasama, H.; Bochtis, D.; Stamoulis, G. Fuzzy Cognitive Map-Based Sustainable Socio-Economic Development Planning for Rural Communities. Sustainability 2019, 12, 305. [CrossRef]

29. Bochtis, D.; Benos, L.; Lampridi, M.; Marinoudi, V.; Pearson, S.; Sørensen, C.G. Agricultural workforce crisis in light of the COVID-19 pandemic. Sustainability 2020, 12, 8212. [CrossRef]

30. Lampridi, M.; Sørensen, C.; Bochtis, D. Agricultural Sustainability: A Review of Concepts and Methods. Sustainability 2019, 11, 5120. [CrossRef]

31. Angelopoulou, T.; Balafoutis, A.; Zalidis, G.; Bochtis, D. From Laboratory to Proximal Sensing Spectroscopy for Soil Organic Carbon Estimation-A Review. Sustainability 2020, 12, 443. [CrossRef]

Publisher's Note: MDPI stays neutral with regard to jurisdictional claims in published maps and institutional affiliations.

(C) 2020 by the authors. Licensee MDPI, Basel, Switzerland. This article is an open access article distributed under the terms and conditions of the Creative Commons Attribution (CC BY) license (http://creativecommons.org/licenses/by/4.0/). 